\title{
Identify glioma recurrence and treatment effects with triple-tracer PET/CT
}

\author{
Cong $\mathrm{Li}^{1+}$, Chang $\mathrm{Yi}^{2+}{ }^{+}$, Yingshen Chen ${ }^{1 \dagger}$, Shaoyan $\mathrm{Xi}^{1}$, Chengcheng Guo ${ }^{1}$, Qunying Yang ${ }^{1}$, Jian Wang ${ }^{1}$, Ke Sai ${ }^{1}$, \\ Ji Zhang ${ }^{1}$, Chao Ke ${ }^{1}$, Fanfan Chen ${ }^{3}$, Yanchun Lv ${ }^{1}$, Xiangsong Zhang ${ }^{2^{*}}$ and Zhongping Chen ${ }^{1^{*}}$ (D)
}

\begin{abstract}
Background: Differential diagnosis of tumour recurrence (TuR) from treatment effects (TrE), mostly induced by radiotherapy and chemotherapy, is still difficult by using conventional computed tomography (CT) or magnetic resonance (MR) imaging. We have investigated the diagnostic performance of PET/CT with 3 tracers, ${ }^{13} \mathrm{~N}^{-\mathrm{NH}_{3},}{ }^{18} \mathrm{~F}-\mathrm{FDOPA}$, and ${ }^{18} \mathrm{~F}-\mathrm{FDG}$, to identify TuR and TrE in glioma patients following treatment.
\end{abstract}

Methods: Forty-three patients with MR-suspected recurrent glioma were included. The maximum and mean standardized uptake values (SUVmax and SUVmean) of the lesion and the lesion-to-normal grey-matter cortex uptake (L/G) ratio were obtained from each tracer PET/CT. TuR or TrE was determined by histopathology or clinical MR follow-up for at least 6 months.

Results: In this cohort, 34 patients were confirmed to have TuR, and 9 patients met the diagnostic standard of TrE. The SUVmax and SUVmean of ${ }^{13} \mathrm{~N}_{-} \mathrm{NH}_{3}$ and ${ }^{18} \mathrm{~F}$-FDOPA PET/CT at TuR lesions were significantly higher compared with normal brain tissue $\left({ }^{13} \mathrm{~N}-\mathrm{NH}_{3} 0.696 \pm 0.558,0.625 \pm 0.507\right.$ vs $0.486 \pm 0.413 ;{ }^{18} \mathrm{~F}-\mathrm{FDOPA} 0.455 \pm 0.518,0.415 \pm 0.477$ vs $0.194 \pm 0.203$; both $P<0.01)$, but there was no significant difference in ${ }^{18} \mathrm{~F}$-FDG $(6.918 \pm 3.190,6.016 \pm 2.807$ vs $6.356 \pm 3.104, P=0.290$ and 0.493$)$. L/G ratios of ${ }^{13} \mathrm{~N}^{-\mathrm{NH}_{3}}$ and ${ }^{18} \mathrm{~F}-\mathrm{FDOPA}$ were significantly higher in TuR than in $\operatorname{TrE}$ group $\left({ }^{13} \mathrm{~N}-\mathrm{NH}_{3}, 1.573 \pm 0.099\right.$ vs $1.025 \pm 0.128, P=0.008 ;{ }^{18} \mathrm{~F}-\mathrm{FDOPA}, 2.729 \pm 0.131$ vs $\left.1.514 \pm 0.141, P<0.001\right)$. The sensitivity, specificity and AUC (area under the curve) by ROC (receiver operating characteristic) analysis were $57.7 \%$, $100 \%$ and 0.803 , for ${ }^{13} \mathrm{~N}_{-} \mathrm{NH}_{3} ; 84.6 \%, 100 \%$ and 0.938 , for ${ }^{18} \mathrm{~F}-\mathrm{FDOPA}$; and $80.8 \%, 100 \%$, and 0.952 , for the combination, respectively.

Conclusion: Our results suggest that although multiple tracer PET/CT may improve differential diagnosis efficacy, for glioma TuR from TrE, ${ }^{18} \mathrm{~F}$-FDOPA PET-CT is the most reliable. The combination of ${ }^{18} \mathrm{~F}$-FDOPA and ${ }^{13} \mathrm{~N}_{-} \mathrm{NH}_{3}$ does not increase the diagnostic efficiency, while ${ }^{18}$ F-FDG is not worthy for differential diagnosis of glioma TuR and TrE.

Keywords: ${ }^{18} \mathrm{~F}-\mathrm{FDOPA},{ }^{13} \mathrm{~N}-\mathrm{NH}_{3},{ }^{18} \mathrm{~F}-\mathrm{FDG}$, Glioma recurrence, Treatment effects

*Correspondence: zhxiangs@mail.sysu.edu.cn; chenzhp@sysucc.org.cn ${ }^{\dagger}$ Cong Li, Chang Yi, Yingshen Chen have contributed equally to this work. 1 Sun Yat-Sen University Cancer Center, State Key Laboratory of Oncology in South China, Collaborative Innovation Center for Cancer Medicine, Guangzhou 510060, China

${ }^{2}$ Department of Nuclear Medicine, The First Affiliated Hospital of Sun YatSen University, Guangzhou 510080, China

Full list of author information is available at the end of the article

\begin{abstract}
Introduction
Glioma is the most common primary brain tumours, and the prognosis of patients with high-grade glioma is very poor [1]. Despite first-line treatments, including maximal safe surgical resection, irradiation, and adjuvant chemotherapy, the median survival time for most malignant glioblastoma patients is still only $12-15$ months [2]. Recurrence is a critical clinical problem in glioma patients, but the diagnosis of recurrent glioma is difficult
\end{abstract}

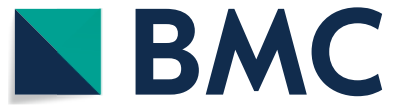

(c) The Author(s) 2021. This article is licensed under a Creative Commons Attribution 4.0 International License, which permits use, sharing, adaptation, distribution and reproduction in any medium or format, as long as you give appropriate credit to the original author(s) and the source, provide a link to the Creative Commons licence, and indicate if changes were made. The images or other third party material in this article are included in the article's Creative Commons licence, unless indicated otherwise in a credit line to the material. If material is not included in the article's Creative Commons licence and your intended use is not permitted by statutory regulation or exceeds the permitted use, you will need to obtain permission directly from the copyright holder. To view a copy of this licence, visit http://creativecommons.org/licenses/by/4.0/. The Creative Commons Public Domain Dedication waiver (http://creativecommons.org/publicdomain/zero/1.0/) applies to the data made available in this article, unless otherwise stated in a credit line to the data. 
using computed tomography $(\mathrm{CT})$ or magnetic resonance (MR) imaging because radiotherapy and chemotherapy are associated with a high incidence of treatment-related imaging changes termed treatment effects ( $\operatorname{TrE})$, which is occasionally referred to as pseudoprogression and radiation necrosis. This phenomenon is believed to be related to the destruction of the blood-brain barrier after radiation therapy and chemotherapy, leading to increased leakiness of contrast agent exhibiting enhancement in the area on MR imaging, which is similar to the imaging findings of tumour recurrence (TuR) [3]. Although advanced multimodal MR imaging plays an important role in the post-treatment follow-up of glioma patient care in recent years, the differential diagnosis in clinical image evaluation between $\operatorname{TrE}$ and TuR in glioma patients remains challenging because they have overlapping clinical and radiologic features [4-6]. The diagnosis of TuR requires a change in the therapeutic approach to a more active antitumour strategy, whereas a diagnosis of TrE supports the effectiveness of current treatment. Therefore, accurate and reliable imaging evaluation is very important for making clinical decisions.

Positron emission tomography/computed tomography (PET/CT) is a molecular imaging technique allowing in vivo quantitative measurement of biological processes noninvasively, which has become an integral supplemental imaging tool for differential diagnosis of brain lesions beyond MR [7]. Some PET tracers, such as ${ }^{18}$ F-fluorodeoxyglucose $\left({ }^{18} \mathrm{~F}\right.$-FDG), ${ }^{13} \mathrm{~N}$-ammonia $\left({ }^{13} \mathrm{~N}-\mathrm{NH}_{3}\right)$, ${ }^{11} \mathrm{C}$-methylmethionine $\quad\left({ }^{11} \mathrm{C}\right.$-MET $),{ }^{18} \mathrm{~F}$-fluoroethyl-Ltyrosine $\left({ }^{18} \mathrm{~F}-\mathrm{FET}\right)$, and ${ }^{18} \mathrm{~F}$-fluoro-L-dihydroxy-phenylalanine $\left({ }^{18} \mathrm{~F}\right.$-FDOPA), have been used for imaging gliomas [7-10]. The Response Assessment in NeuroOncology working group and European Association for Neuro-Oncology have also recommended the clinical use of PET/CT imaging in gliomas, and they emphasize that PET/CT exhibits increased diagnostic accuracy than MR when differentiating TuR from TrE [11]. However, no standard imaging technology is currently available to achieve a differential diagnosis, and few articles compare different metabolic types of PET/CT tracers used in this critical issue of the glioma follow-up process. This study aims to explore the clinical potential of ${ }^{13} \mathrm{~N}-\mathrm{NH}_{3}$, ${ }^{18} \mathrm{~F}$-FDOPA, and ${ }^{18} \mathrm{~F}$-FDG PET/CT, which represent three different types of tracers in the differential diagnosis of TuR and TrE in glioma patients, to reduce clinical misdiagnosis.

\section{Materials and methods Patients}

Patients treated at our hospital between September 2016 and December 2019 with suspicion of recurrent gliomas based on MR imaging demonstrating new enhancement lesions and the desire for PET/CT examination were included in this study. The initial diagnosis for these patients with histopathologic glioma according to revised 2016 World Health Organization (WHO) criteria, and TuR or TrE diagnosis was determined by histology if the patient received repeated surgical resection or standard clinical MR follow-up for at least 6 months at 2- to 3-month intervals after the PET/CT exam. This study was approved by the ethics committee of our cancer centre, and informed consent was obtained from all individual participants included in the study.

Forty-three patients (16 females and 27 males) were enrolled in the study. The average age was $41.74 \pm 12.71$ years (range, 14-65 years). Thirty-four patients received all three tracer examinations. Three patients only underwent ${ }^{13} \mathrm{~N}-\mathrm{NH}_{3}$ and ${ }^{18} \mathrm{~F}$-FDG PET/CT, and six patients only underwent ${ }^{18} \mathrm{~F}$-FDOPA PET/CT due to the patient's desire or shortage of tracers. Detailed patient characteristics of each tracer are listed in Table 1. Except for one patient's lesion located in the left cerebellum, the other patients' lesions were mainly located in the temporal lobe, frontal lobe or parietal lobe, including 23 cases on the right side and 19 cases on the left side. All patients received radiotherapy before, and the mean dose was 59.23 \pm 1.84 Gy (range, 54-66 Gy). Only one patient did not receive adjuvant chemotherapy and the others received temozolomide-based adjuvant chemotherapy. The median interval time from primary diagnosis to PET/CT examination was 19.10 months (range,

Table 1 Patient characteristics of each PET/CT tracer

\begin{tabular}{lllll}
\hline Characteristics & & \multicolumn{2}{l}{ PET } \\
\cline { 3 - 5 } & N & NH3 & DOPA & FDG \\
\hline N & 43 & 34 & 43 & 37 \\
Gender & & & & \\
Male & 27 & 20 & 27 & 23 \\
Female & 16 & 14 & 16 & 14 \\
Age (years) & $38.5 \pm 6.37$ & $40.38 \pm 12.41$ & $38.5 \pm 6.37$ & $40.28 \pm 6.36$ \\
WHO grade & & & & \\
II & 12 & 11 & 12 & 12 \\
III & 15 & 10 & 15 & 11 \\
IV & 16 & 13 & 16 & 14 \\
IDH1 & & & & \\
Mutation & 24 & 21 & 24 & 21 \\
Wide type & 13 & 7 & 13 & 10 \\
NA & 6 & 6 & 6 & 6 \\
Final diagnosis & & & & \\
TuR & 34 & 26 & 34 & 29 \\
TrE & 9 & 8 & 9 & 8
\end{tabular}

WHO World Health Organization, NA not achieved, TuR tumour recurrence, TrE treatment effects 
4.10-88.20 months). The median interval between radiotherapy and PET/CT was 15.90 months (range, 1.67-84.77 months).

\section{PET/CT imaging protocol}

Tracers were synthesized through a commercially available system for isotope generation (Cyclone-10, Ion Beam Applications S.A., Belgium; AllinOne synthesizer, Trasis, Belgium). ${ }^{13} \mathrm{~N}-\mathrm{NH}_{3}$ and ${ }^{18} \mathrm{~F}$-FDG were produced as previously mentioned [7]. ${ }^{18} \mathrm{~F}$-FDOPA was produced using the method of Libert et al. [12]. The radio-chemical purity of ${ }^{13} \mathrm{~N}-\mathrm{NH}_{3}$ was $>99 \%,{ }^{18} \mathrm{~F}$-FDOPA was $>98 \%$, and ${ }^{18} \mathrm{~F}$ FDG was $>95 \%$. PET/CT examinations were performed on a Gemini GXL 16 scanner (Philips, Netherlands) in 3-dimensional acquisition mode. The reconstruction protocols of PET/CT have been published in detail previously [7]. Briefly, patients underwent a fast for at least $4 \mathrm{~h}$ before the ${ }^{18} \mathrm{~F}$-FDOPA examination. Ten minutes after the intravenous injection of $2 \mathrm{MBq} / \mathrm{kg}$ of ${ }^{18} \mathrm{~F}$-FDOPA, a dedicated CT scan of the brain $(120 \mathrm{kV}, 80 \mathrm{mAs}, 3 \mathrm{~mm}$ slice collimation) was performed followed by a braincentred static 3D PET acquisition of $10 \mathrm{~min}$. Then, a clear PET image was obtained. ${ }^{18}$ F-FDG PET/CT was performed after ${ }^{13} \mathrm{~N}-\mathrm{NH}_{3}$ with a minimum interval of $2 \mathrm{~h}$ on another day within 1 week, and patients remained untreated until the PET/CT study was completed. All patients had fasted for at least $6 \mathrm{~h}$ before ${ }^{13} \mathrm{~N}-\mathrm{NH}_{3}$ and ${ }^{18} \mathrm{~F}$-FDG examination. First, after intravenous injection of $7.4 \mathrm{MBq}(0.20 \mathrm{mCi}) / \mathrm{kg}$ of ${ }^{13} \mathrm{~N}-\mathrm{NH}_{3}$, patients rested in a quiet room, and $\mathrm{PET} / \mathrm{CT}$ was performed $10 \mathrm{~min}$ later. Then, a dose of $5.18 \mathrm{MBq}(0.14 \mathrm{mCi}) / \mathrm{kg}{ }^{18} \mathrm{~F}-\mathrm{FDG}$ was injected intravenously, and serial scanning was performed approximately 30-45 min after the injection with the patient resting with their eyes closed. Finally, PET/ CT images were reconstructed using the LOR-RAMLA algorithm with low-dose CT images for attenuation correction.

\section{PET image parameters}

PET/CT images were evaluated by two experienced nuclear medicine physicians independently who were blinded to the final clinical diagnosis of the lesions. The tracers' uptake of the lesion was evaluated by quantitative analysis. A region of interest (ROI) was placed over the entire lesion on the transverse PET/CT image by the nuclear physicians. For lesions with reduced or equal uptake, the ROI was drawn based on the anatomical information on the brain lesions presented by previous MR. The grey-matter ROI was drawn in the lobe contralateral to the lesion according to the method we reported before $[13,14]$. After reaching the consensus of the target lesions and ROI, the maximum and mean standardized uptake value (SUV) of the lesion was detected as SUVmax and SUVmean. The lesion-to-normal grey-matter cortex uptake (L/G) ratio was calculated as the SUVmax of the lesion divided by the average SUV of the contralateral normal grey-matter (CNGM) cortex.

\section{True diagnosis of lesion}

TuR or TrE was determined by histopathology if repeated surgical resection was performed. When the histopathologic examination was not available, clinical followup, including longitudinal MR and clinical symptoms, was considered the standard of truth according to the Response Assessment in Neuro-Oncology (RANO) criteria [15] and our previous report $[4,16]$. Briefly, the lesion was defined as TuR based on a progressive increase in size and/or the number of enhancing lesions with the development of neurologic symptoms. TrE was defined based on a reduced or stable lesion size on subsequent follow-up images with a stable or improved clinical condition for at least 6 months without additional steroid treatment.

\section{Statistical analysis}

All statistical analyses were performed using IBM SPSS Statistics 23.0 (SPSS Inc. Chicago, IL, USA) software. Continuous variables are expressed as the mean \pm standard deviation (SD) or medians with range. Student's $\mathrm{t}$-test or Chi-square tests were used to compare the differences between the TuR and TrE groups. A paired Student's t-test was used to compare lesions and CNGM within each PET/CT tracer. The overall survival of glioma patients after PET/CT examination was evaluated using the log rank test with Kaplan-Meier analysis. The receiver operating characteristic (ROC) curve was chosen to assess the performance of PET/CT parameters in differentiating between TuR and TrE. The optimal cutoff values were determined by maximizing the Youden's index value. $P<0.05$ was considered statistically significant.

\section{Results}

Tumour recurrence (TuR) and treatment effects (TrE)

Finally, thirty-four patients were diagnosed with TuR, whereas the remaining 9 were diagnosed with TrE. Note that seven patients were diagnosed from histopathology after reoperation, and the remaining patients were diagnosed based on clinical and radiological follow-up for more than 6 months. TrE occurred more frequently in females $(7 / 16,43.75 \%)$ compared with males $(2 / 27$, $7.41 \%)(P=0.02)$. Among the 37 patients with IDH1 mutation status results, the probability of IDH1 mutation in the TrE group was $100 \%(8 / 8)$, whereas that in the TuR group was $55.17 \%(16 / 29)(P=0.03)$. The two groups exhibited no significant differences in terms of patients' 
age $(P=0.54)$, WHO grade $(P=0.09)$, radiotherapy dose $(P=0.37)$ or the time interval between radiotherapy and diagnosis surgery $(P=0.36$ and 0.39$)$ (Table 2). The median follow-up time from PET/CT performed was 10.23 months (95\% CI, 9.26-14.63 months). KaplanMeier analysis showed that patients diagnosed with $\operatorname{TrE}$ exhibited improved survival compared with those diagnosed with TuR (log-rank test, $\mathrm{x}^{2}=5.524, P=0.019$ ) (Fig. 1).

\section{PET/CT findings}

The SUVmax and SUVmean of lesions were significantly increased compared with the SUVmean of contralateral normal grey matter $(\mathrm{CNGM})$ in ${ }^{13} \mathrm{~N}-\mathrm{NH}_{3}$ and ${ }^{18} \mathrm{~F}$-FDOPA PET $\left({ }^{13} \mathrm{~N}-\mathrm{NH}_{3} 0.696 \pm 0.558,0.625 \pm 0.507\right.$ vs $0.486 \pm 0.413 ;{ }^{18} \mathrm{~F}$-FDOPA $0.455 \pm 0.518,0.415 \pm 0.477$ vs $0.194 \pm 0.203$; both $P<0.01$ ), but there was no significant difference in ${ }^{18} \mathrm{~F}$-FDG $(6.918 \pm 3.190,6.016 \pm 2.807$ vs $6.356 \pm 3.104, P=0.290$ and 0.493 ) (Fig. $2 \mathrm{a}-\mathrm{c}$ ).

The lesions' SUVmax and SUVmean of ${ }^{13} \mathrm{~N}^{-\mathrm{NH}_{3}}$ were significantly different in patients with TuR compared to patients with $\operatorname{TrE}$ (Fig. 2b), whereas TuR exhibited significantly increased L/G ratios than TrE both in ${ }^{13} \mathrm{~N}$ $\mathrm{NH}_{3}$ and ${ }^{18} \mathrm{~F}$-FDOPA PET/CT $\left({ }^{13} \mathrm{~N}-\mathrm{NH}_{3}, 1.573 \pm 0.099\right.$ vs $1.025 \pm 0.128, P=0.008 ;{ }^{18} \mathrm{~F}-\mathrm{FDOPA}, 2.729 \pm 0.131$ vs $1.514 \pm 0.141, P<0.001$ ) but not in ${ }^{18}$ F-FDG (Fig. $2 \mathrm{~d}$ ). Figures 3 and 4 report different PET/CT performances in two typical cases of TuR and TrE.

ROC analysis for differentiation between TuR and TrE yielded an optimal $\mathrm{L} / \mathrm{G}$ ratio of 2.165 for ${ }^{18} \mathrm{~F}-\mathrm{FDOPA}$

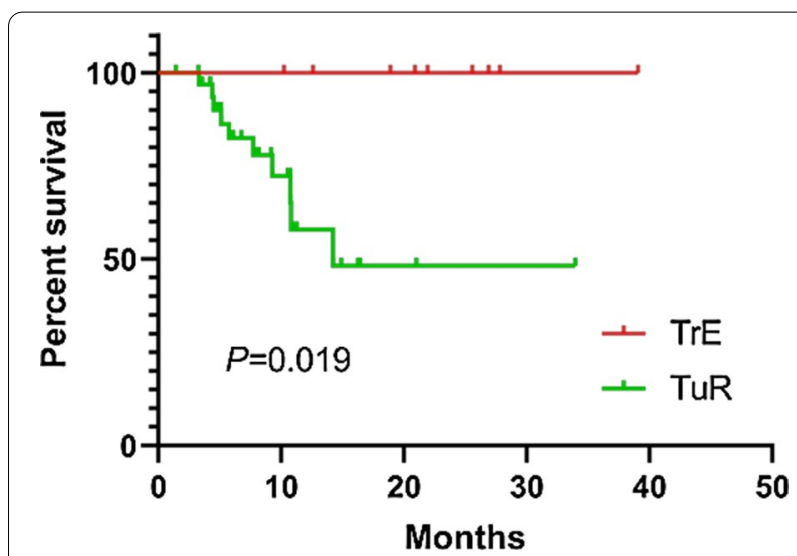

Fig. 1 The overall survival curves of glioma patients after PET/CT examination according to final diagnosis with $\operatorname{TrE}$ and TuR

(sensitivity, 84.6\%; specificity, 100\%; AUC, 0.938; 95\% CI [0.859-1.000];), 1.260 for ${ }^{18} \mathrm{~F}$-FDG (sensitivity, 46.2\%; specificity, $100 \%$; AUC, 0.726 ; $95 \%$ CI [0.547$0.905]$;), and 1.515 for ${ }^{13} \mathrm{~N}^{-\mathrm{NH}_{3}}$ (sensitivity, 57.7\%; specificity, 100\%; AUC, 0.726; 95\% CI [0.547-0.905]) (Table 3 ). The $\mathrm{L} / \mathrm{G}$ ratio of ${ }^{18} \mathrm{~F}$-FDOPA exhibited the best PET/CT parameters compared to ${ }^{18} \mathrm{~F}$-FDG and ${ }^{13} \mathrm{~N}_{-} \mathrm{NH}_{3}$. The area under the ROC curves of the $\mathrm{L} / \mathrm{G}$ ratio evaluation of ${ }^{13} \mathrm{~N}-\mathrm{NH}_{3}$ and ${ }^{18} \mathrm{~F}$-FDOPA was 0.803 and 0.938 , respectively (Fig. 5). Combining the L/G ratio evaluation of ${ }^{18} \mathrm{~F}$-FDOPA and ${ }^{13} \mathrm{~N}-\mathrm{NH}_{3}$, the diagnostic performance did not show further improvement, yielding a sensitivity of $80.8 \%$, a specificity of $100 \%$, and an AUC of 0.952.

Table 2 Patient characteristics of TuR and TrE

\begin{tabular}{|c|c|c|c|c|}
\hline Characteristics & TuR & TrE & & $P$ values \\
\hline N & 34 & 9 & & \\
\hline \multicolumn{5}{|l|}{ Gender } \\
\hline Male & 25 & 2 & $X^{2}=8.02$ & $0.02^{*}$ \\
\hline Female & 9 & 7 & & \\
\hline Age (years) & $41.12 \pm 12.52$ & $44.11 \pm 13.91$ & $t=0.62$ & 0.54 \\
\hline \multicolumn{5}{|l|}{ WHO grade } \\
\hline$\|$ & 10 & 2 & & \\
\hline III & 10 & 6 & $x^{2}=4.63$ & 0.09 \\
\hline IV & 14 & 1 & & \\
\hline \multicolumn{5}{|l|}{ IDHI } \\
\hline Mutation & 16 & 8 & $x^{2}=5.53$ & $0.03^{*}$ \\
\hline Wide type & 13 & 0 & & \\
\hline Dose of RT (Gy) & $59.41 \pm 1.81$ & $58.78 \pm 1.99$ & $t=-0.92$ & 0.37 \\
\hline interval from RT (Mon.) & $22.51 \pm 21.05$ & $29.61 \pm 16.61$ & $t=0.93$ & 0.36 \\
\hline interval from First Diagnosis (Mon.) & $25.29 \pm 21.28$ & $32.03 \pm 16.57$ & $t=0.88$ & 0.39 \\
\hline
\end{tabular}



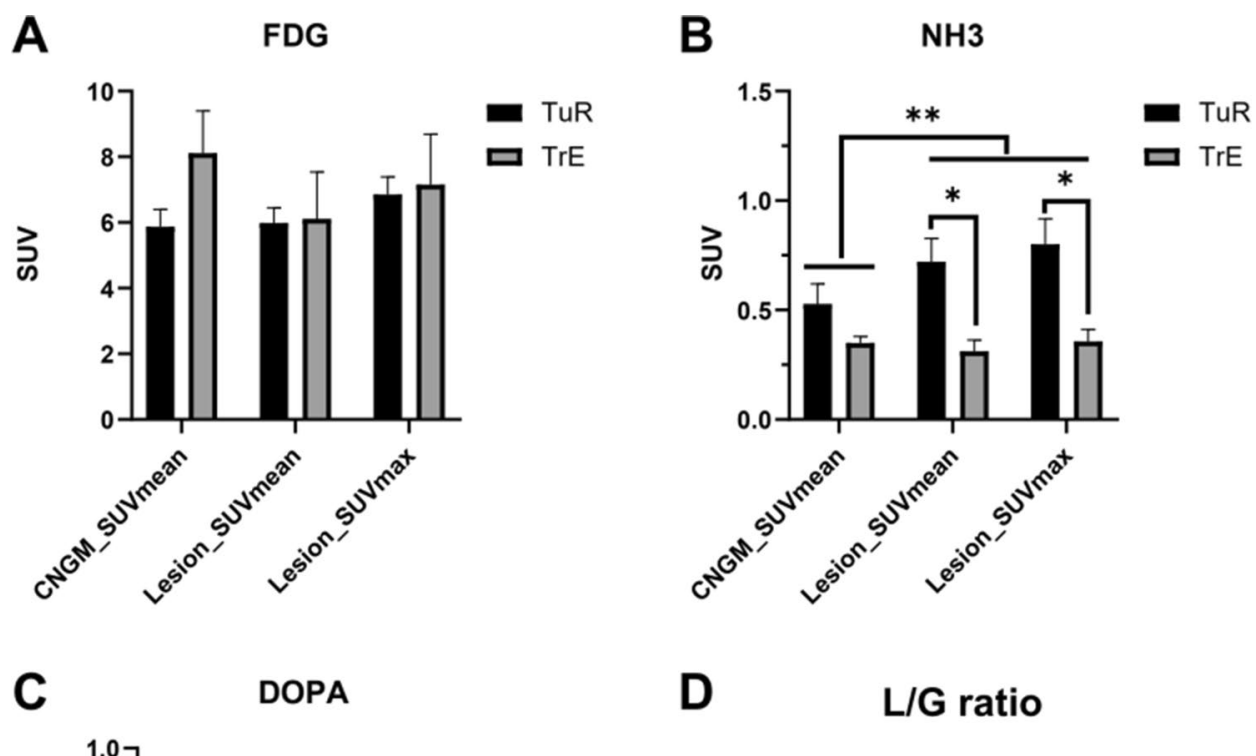

D L/G ratio
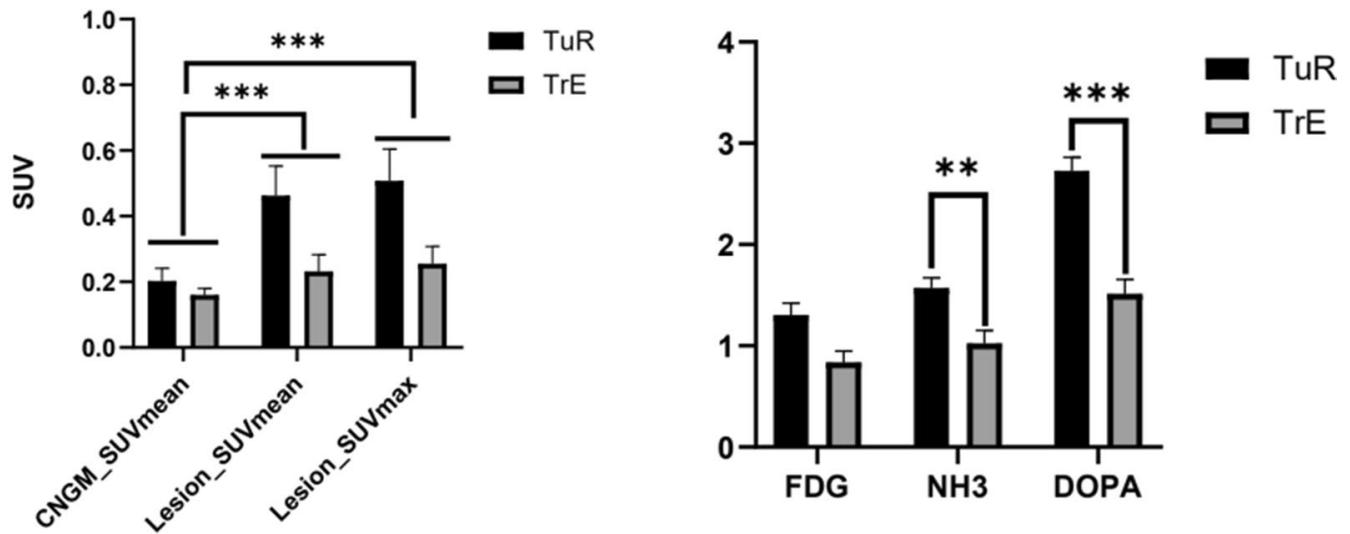

Fig. 2 The SUVmax and SUVmean of the lesions compared with SUVmean of CNGM and with groups of TuR and TrE in different PET tracers (a ${ }^{18} \mathrm{~F}-\mathrm{FDG} ; \boldsymbol{b}^{13} \mathrm{~N}-\mathrm{NH}_{3} ; \mathbf{c}^{18} \mathrm{~F}$-FDOPA). The L/G ratios of ${ }^{18} \mathrm{~F}-\mathrm{FDG},{ }^{13} \mathrm{~N}-\mathrm{NH}_{3}$ and ${ }^{18} \mathrm{~F}-\mathrm{FDOPA}$ were compared in the TuR and $\operatorname{TrE}$ groups $(\mathbf{d}) .{ }^{*} P<0.05$, ${ }^{* *} P<0.01$, and ${ }^{* *} P<0.001$
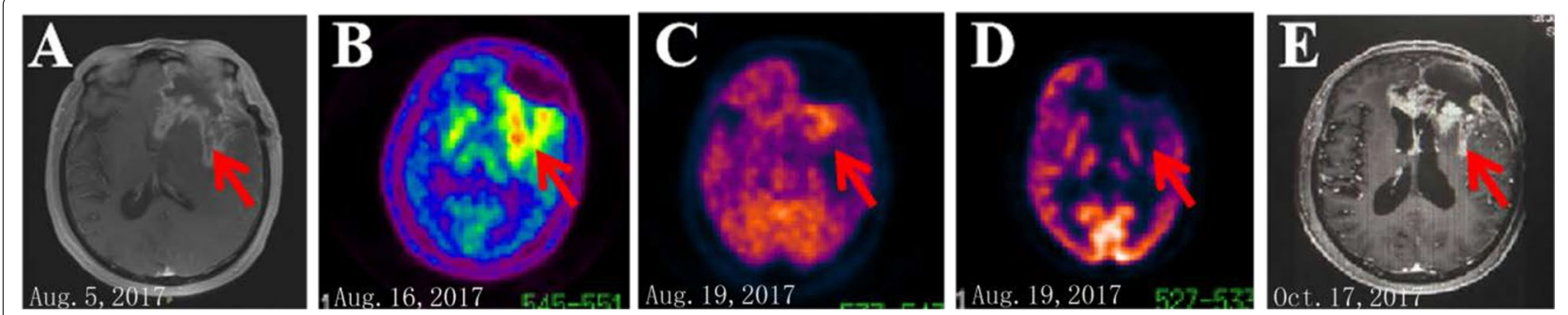

Fig. 3 A representative patient with glioma TuR. Contrast MR image (a) reveals an enhanced lesion with obviously increased uptake of ${ }^{18}$ F-FDOPA (b), slightly increased uptake of ${ }^{13} \mathrm{~N}-\mathrm{NH}_{3}(\mathbf{c})$, and decreased uptake of ${ }^{18} \mathrm{~F}$-FDG $(\mathbf{d})$. Two months later, contrast MR showed that the lesions continued to increase (e), and the patient died 8 months later

\section{Discussion}

The prognosis of patients with gliomas is very poor once recurrence occurs after comprehensive treatment. Some studies have demonstrated that the median survival time of glioma patients is only $9-10$ months after the first tumour recurrence $[17,18]$. Generally, the follow-up of glioma patients after or during comprehensive treatment mainly depends on the MR examination. However, $\operatorname{TrE}$ 

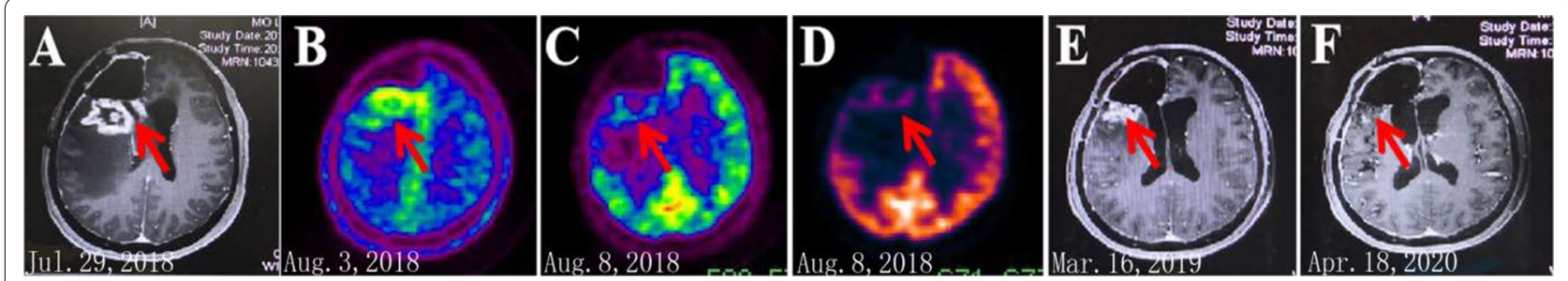

Fig. 4 A representative patient with TrE. Contrast MR image (a) presents an enhanced lesion with slightly increased uptake of ${ }^{18} \mathrm{~F}-\mathrm{FDOPA}(\mathbf{b})$ and no increased uptake of ${ }^{13} \mathrm{~N}-\mathrm{NH}_{3}$ (c) and ${ }^{18} \mathrm{~F}-\mathrm{FDG}(\mathbf{d})$. Follow-up MR revealed that the enhanced lesions gradually decreased and disappeared (e, $\mathbf{f}$ )

Table 3 ROC curve analyses of the L/G ratio of FDG, NH3, DOPA, and the combination of NH3 and DOPA in differentiating TuR and TrE

\begin{tabular}{|c|c|c|c|c|c|c|c|c|}
\hline \multirow[t]{2}{*}{ PET index } & \multirow[t]{2}{*}{ AUC } & \multirow[t]{2}{*}{ SE of AUC } & \multirow[t]{2}{*}{$P$ values } & \multicolumn{2}{|c|}{$95 \% \mathrm{Cl}$} & \multirow[b]{2}{*}{ Optimal cutoff } & \multirow[b]{2}{*}{ Specificity\% } & \multirow[b]{2}{*}{ Sensitivity\% } \\
\hline & & & & lower & upper & & & \\
\hline FDG & .726 & .091 & .056 & .547 & .905 & 1.260 & 100 & 46.2 \\
\hline $\mathrm{NH3}$ & .803 & .081 & .011 & .644 & .962 & 1.515 & 100 & 57.7 \\
\hline DOPA & .938 & .040 & .000 & .859 & 1.000 & 2.165 & 100 & 84.6 \\
\hline $\mathrm{DOPA}+\mathrm{NH} 3$ & .952 & .035 & .000 & .883 & 1.000 & 0.832 & 100 & 80.8 \\
\hline
\end{tabular}

AUC area under curve, SE standard error, TuR tumour recurrence, TrE treatment effects

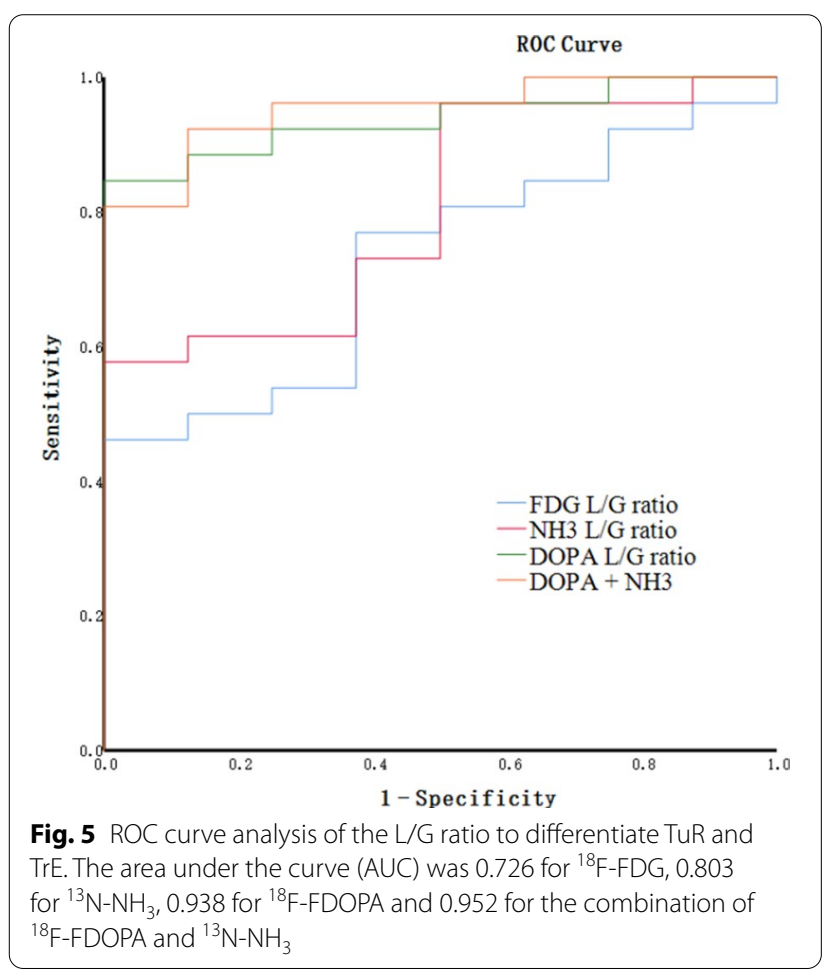

may lead to mimicking of tumour recurrence because they exhibit similar features on contrast-enhanced MR, which are also known as early effects (i.e., pseudoprogression) or late effects, such as radiation necrosis mainly based on timing. Although pseudoprogression and radiation necrosis are thought to represent distinct clinical and pathophysiologic mechanisms, they share many histologic similarities, such as inflammatory infiltrates and necrosis, which translate into similar imaging characteristics [19]. This similarity makes it difficult to identify TuR and TrE with the most commonly used MR images, especially contrast-enhanced MR. Although several advanced MR techniques, such as amide proton transfer, diffusion, perfusion, and spectroscopy imaging, can improve the differential diagnosis and are widely used in clinical applications [4,20], their accuracy and efficacy remain limited. The final diagnosis requires longitudinal MR observation for several months or repeat surgery. This process is resource-intensive as well as burdensome for the patients, and the longitudinal MR observation also delays definitive treatment. Then, experienced doctors will use PET/CT, which can reflect the metabolism of lesions, to assist MR for optimal diagnosis.

In this study, we investigated the diagnostic performance of multitracer PET/CT techniques, including ${ }^{13} \mathrm{~N}$ $\mathrm{NH}_{3},{ }^{18} \mathrm{~F}$-FDOPA, and ${ }^{18} \mathrm{~F}$-FDG, in distinguishing TuR from $\mathrm{TrE}$ in a cohort of patients with suspected recurrent gliomas. ${ }^{18} \mathrm{~F}-\mathrm{FDG}$ is the most widely used tracer in PET/ CT imaging and reflects the glucose metabolism level of tumours, especially malignant tumours. However, ${ }^{18} \mathrm{~F}$ FDG may have some limitations in differentiating intracranial tumours with low metabolic levels from normal brain tissues, inflammation, and benign tumours because it accumulates largely in normal brain tissue, leading to small differences between glioma lesions and normal 
brain tissue [21]. Therefore, ${ }^{18} \mathrm{~F}$-FDG is not very good for glioma display, especially for low-grade glioma and lesions close to grey matter. This limitation was also confirmed in this study, in which ${ }^{18} \mathrm{~F}$-FDG metabolism was not significantly different between lesions and contralateral grey cortical tissue. The low L/G ratio also limits its role in the differential diagnosis of TuR and TrE, and no significant difference was found in this study.

${ }^{13} \mathrm{~N}_{-} \mathrm{NH}_{3}$ is another PET imaging agent that is low fat-soluble and has a small diameter, allowing it to penetrate the blood-brain barrier (BBB). We have previously reported that the uptake of ${ }^{13} \mathrm{~N}-\mathrm{NH}_{3}$ is superior to ${ }^{18} \mathrm{~F}$ FDG not only in enabling differentiation between glioma and non-neoplastic lesions but also in separating lowgrade gliomas (LGG) from high-grade gliomas [13, 14]. This difference may be due to the uptake of ${ }^{13} \mathrm{~N}-\mathrm{NH}_{3}$ in normal brain tissue being relatively lower than ${ }^{18} \mathrm{~F}$-FDG, whereas the uptake of ${ }^{13} \mathrm{~N}-\mathrm{NH}_{3}$ in glioma is significantly increased. Therefore, the $\mathrm{L} / \mathrm{G}$ ratio of ${ }^{13} \mathrm{~N}-\mathrm{NH}_{3} \mathrm{PET} / \mathrm{CT}$ imaging is higher in tumourous lesions, making it more beneficial to distinguish glioma from some inflammatory or benign tumours. Furthermore, our other study [9] also found that the increased ${ }^{13} \mathrm{~N}-\mathrm{NH}_{3}$ uptake in recurrent glioma and the absent or lower uptake in radiation necrosis due to perfusion and glutamine synthetase activity in the recurrent tumour is higher than that in the TrE. In this study, we also found that ${ }^{13} \mathrm{~N}-\mathrm{NH}_{3}$ is a promising tracer for separating TuR from TrE. In addition, SUVmax, SUVmean, and L/G ratio all showed good performance for this purpose, and their role seemed superior to ${ }^{18} \mathrm{~F}$-FDG.

Because gliomas have upregulated amino acid transporters and increased amino acid metabolism, and labelled amino acid tracers, including ${ }^{11} \mathrm{C}$-MET, ${ }^{18} \mathrm{~F}$-FET, and ${ }^{18} \mathrm{~F}$-FDOPA, are increasingly being widely used in gliomas in recent years with better tumour-to-background contrast for differentiation glioma grade, biopsy guiding, radiotherapy planning, therapy monitoring, and differentiation between $\operatorname{TrE}$ and residual or recurrent glioma [21-23]. Amino acid PET/CT typically demonstrates high uptake in glioma and low uptake in the normal brain; thus, the L/G ratio exhibits advantages over SUVmax and SUVmean of the lesion. These amino acid tracers can be used in PET/CT for suspicion of recurrent glioma based on pathophysiological differences between the actively growing tumour, which exhibits increased transport and metabolism of the amino acid; conversely, treatment-induced brain changes result in a low level of metabolism in lesions. For example, Martinez-Amador et al. [24] applied an L/CP SUVmax index to differentiate post-therapeutic changes from tumour presence with a sensitivity of $89.3 \%$, specificity of $90.0 \%$, positive predictive value of $96.1 \%$, negative predictive value of $75 \%$, and accuracy of $82.9 \%$. Hotta Masatoshi et al. [25] found that ${ }^{11} \mathrm{C}$-MET radiomics yielded excellent outcomes for differentiating recurrent brain tumours from radiation necrosis, which outperformed the $\mathrm{T} / \mathrm{N}$ ratio evaluation with areas under the curve of 0.98 and 0.73 . This result means that ${ }^{11} \mathrm{C}$-MET PET/CT is useful in differentiating glioma TuR from TrE. However, another study suggests that increased uptake of ${ }^{11} \mathrm{C}$-MET, such as ${ }^{18}$ F-FDG, may have limited specificity in distinguishing inflammatory lesions from tumours [26]. Bashir et al. [27] found that a 20-min ${ }^{18} \mathrm{~F}$-FET PET scan is a powerful tool with TBRmax (sensitivity $99 \%$, specificity $94 \%$ ) to distinguish posttreatment changes from recurrent glioblastoma 6 months postradiotherapy. Bogsrud et al. [28] reported the performance of a new type of amino acid ${ }^{18} \mathrm{~F}$-fluciclovine in PET/CT of suspected residual or recurrent glioma, but the ability of ${ }^{18} \mathrm{~F}$-fluciclovine PET/CT to discriminate between recurrent glioma and treatment-related changes could not be determined because no patients had confirmed treatment-related changes. More recently, ${ }^{18} \mathrm{~F}$-labelled DOPA is a more widely used amino acid tracer than ${ }^{11} \mathrm{C}$-MET because it has a longer half-life of up to $110 \mathrm{~min}$, whereas that of ${ }^{11} \mathrm{C}$-MET is only $20 \mathrm{~min}$. Humbert et al. [8] found that ${ }^{18} \mathrm{~F}$-FDOPA PET has a significant impact on the management of patients with a suspicion of brain tumour recurrence, either glioblastoma or brain metastases, but a low impact when used to evaluate residual glioblastoma infiltration after first-line radiochemotherapy or secondline bevacizumab. ${ }^{18} \mathrm{~F}$-FDOPA has been increasingly used in glioma and exhibits potential value in the identification of $\mathrm{TrE}$ and TuR [21].

Some other tracers such as the nucleoside analog ${ }^{18} \mathrm{~F}$-fluorothymidine $\left({ }^{18} \mathrm{~F}\right.$-FLT $)$ and hypoxia tracer ${ }^{18} \mathrm{~F}$-fluoromisonidazole $\left({ }^{18} \mathrm{~F}\right.$-FMISO $)$ also displayed reliable performances in glioma imaging. ${ }^{18} \mathrm{~F}$-FLT can reflect tumor proliferation rate and be a marker of glioma aggressiveness due to thymidine is a nucleoside encountered in DNA [29, 30]. But it reflects proliferative indices to variable and potentially unreliable extents [31]. Given the low accumulation of ${ }^{18} \mathrm{~F}$-FLT in low-grade gliomas, ${ }^{18}$ F-FLT PET/CT should not be used in low-grade recurrent gliomas [32]. What's more, Enslow et al. [33] found there was no significant difference between $\operatorname{TrE}$ and TuR with regard to SUVmax parameter of ${ }^{18} \mathrm{~F}$-FLT $\mathrm{PET} / \mathrm{CT}$. ${ }^{18} \mathrm{~F}$-FMISO is the most common radiotracer for hypoxia imaging which can distinguish glioblastomas from lower-grade gliomas due to glioblastomas presents with necrosis and hypoxic environment, whereas lowergrade gliomas do not develop necrosis, and ${ }^{18} \mathrm{~F}$-FMISO $\mathrm{PET} / \mathrm{CT}$ also can predict the tumor microenvironment, including necrosis, vascularization, and permeability [34]. As ischemia and hypoxia are also important mechanisms of TrE [35], ${ }^{18} \mathrm{~F}$-FMISO PET/CT is limited used in 
differentiating TuR from TrE, but it has potential value to assess treatment response for anti-angiogenic therapy [36].

In the present study, we demonstrated the application of three typical tracers in the detection of recurrent glioma. The overall L/G ratio of ${ }^{18} \mathrm{~F}$-FDOPA and ${ }^{13} \mathrm{~N}$ $\mathrm{NH}_{3}$ is better than that of ${ }^{18} \mathrm{~F}$-FDG. Further ROC analysis showed that the $\mathrm{L} / \mathrm{G}$ ratio of ${ }^{18} \mathrm{~F}$-FDOPA appears to outperform sensitivity to ${ }^{13} \mathrm{~N}-\mathrm{NH}_{3}$ in the assessment of TrE from TuR even when the specificity is $100 \% .{ }^{18} \mathrm{~F}$ FDG itself has no advantage in the diagnosis of recurrent glioma, only ${ }^{13} \mathrm{~N}-\mathrm{NH}_{3}$ and ${ }^{18} \mathrm{~F}$-FDOPA are selected for combined diagnosis analysis. Compared with ${ }^{18} \mathrm{~F}$-DOPA alone, the diagnostic sensitivity and efficiency of the combination of ${ }^{18} \mathrm{~F}$-DOPA and ${ }^{13} \mathrm{~N}-\mathrm{NH}_{3}$ have not been improved. These findings suggest that ${ }^{18} \mathrm{~F}$-FDOPA alone may be more acceptable to patients and that the diagnostic effect is equivalent. According to our previous research, this finding may be due to the fact that ${ }^{13} \mathrm{~N}$ $\mathrm{NH}_{3}$ PET/CT has high specificity in the diagnosis of brain tumours compared with nontumour lesions, but the sensitivity is low when differentiating these lesions from LGG, which is consistent with the research results in this paper. There may be a certain degree of similarity in metabolic level between the process of glioma recurrence after chemoradiotherapy and the formation of LGG. Thus, ${ }^{18}$ F-DOPA itself has high specificity (100\%) and sensitivity (84.6\%) in distinguishing TuR and TrE. The combination of low sensitivity ${ }^{13} \mathrm{~N}-\mathrm{NH}_{3} \mathrm{PET} / \mathrm{CT}$ does not help.

To our knowledge, this study is the first comparison among ${ }^{13} \mathrm{~N}-\mathrm{NH}_{3},{ }^{18} \mathrm{~F}-\mathrm{FDG}$ and ${ }^{18} \mathrm{~F}-\mathrm{FDOPA}$ PET/ $\mathrm{CT}$ in patients with suspected glioma recurrence, and ${ }^{18}$ F-FDOPA exhibited good performance in the differential diagnosis of TuR from TrE. However, some limitations in this study should be noted. First, given the influence of reagents and patients' wishes, the sample size in this study is relatively small. Larger sample studies are needed to support our conclusions. Second, this cohort is biased to IDH1 mutated patients (24/37), and most patients were treated almost two years before this investigation. This finding may be due to the prevalence of IDH1 mutation in patients with relatively late recurrence, and IDH1 wild type patients are more likely to identify recurrence because of rapid disease progression. In addition, the high rate of IDH1 mutation on $\mathrm{TrE}$ in our data may be due to the radiosensitization and a less aggressive phenotype of IDH1 mutated gliomas [37]. Third, WHO tumour grade and other molecular profiles, such as $1 \mathrm{p} 19 \mathrm{q}$, may affect the process and metabolic level of glioma recurrence, which is also not further discussed in this study. Moreover, due to the lack of sufficient diagnostic gold standards at present, we can only use pathology combined with follow-up for final diagnosis, which is similar to that noted in many other studies [4, 16, 38, 39]. TrE also includes changes in different periods and TrE or recurrent tumours will often coexist. These tumours are difficult to distinguish in many cases. Finally, the L/G ratio reflects only a single voxel uptake of the lesion and does not include volume-based information; thus, this metric can yield false-negative results due to the obvious heterogeneity of glioma. This notion may be the reason why the sensitivity is relatively low compared with the specificity in this study.

\section{Conclusion}

In conclusion, $\mathrm{PET} / \mathrm{CT}$ is a powerful tool to distinguish glioma TuR from TrE, and ${ }^{18}$ F-FDOPA PET/CT exhibited remarkably improved differential diagnosis efficacy than ${ }^{13} \mathrm{~N}-\mathrm{NH}_{3}$ and ${ }^{18} \mathrm{~F}$-FDG. Moreover, considering that the combination of ${ }^{18} \mathrm{~F}$-FDOPA and ${ }^{13} \mathrm{~N}-\mathrm{NH}_{3}$ shows comparably diagnostic performance with ${ }^{18} \mathrm{~F}$-FDOPA alone, ${ }^{18} \mathrm{~F}$-FDOPA alone is a good choice for effective diagnosis and could facilitate more effective therapeutic decision-making for patients with suspected glioma recurrence. However, this conclusion should be confirmed in more studies with larger samples.

\section{Abbreviations \\ CT: Computed tomography; MR: Magnetic resonance; TrE: Termed treatment effects; TuR: Tumour recurrence; PET/CT: Positron emission tomography/com- puted tomography; ${ }^{18} \mathrm{~F}$-FDG: ${ }^{18} \mathrm{~F}$-fluorodeoxyglucose; ${ }^{13} \mathrm{~N}-\mathrm{NH}_{3}:{ }^{13} \mathrm{~N}$-ammonia; ${ }^{11} \mathrm{C}-\mathrm{MET}:{ }^{11} \mathrm{C}$-methylmethionine; ${ }^{18} \mathrm{~F}$-FET: ${ }^{18} \mathrm{~F}$-fluoroethyl-L-tyrosine; ${ }^{18} \mathrm{~F}$-FDOPA: ${ }^{18} \mathrm{~F}$-fluoro-L-dihydroxy-phenylalanine; ${ }^{18} \mathrm{~F}$-FLT: ${ }^{18} \mathrm{~F}$-fluorothymidine; ${ }^{18} \mathrm{~F}$-FMISO: ${ }^{18}$ F-fluoromisonidazole; WHO: World Health Organization; ROI: Region of interest; SUV: Standardized uptake value; L/G: Lesion-to-normal grey-matter cortex; CNGM: Contralateral normal grey-matter; RANO: Response Assessment in Neuro-Oncology; ROC: Receiver operating characteristic; BBB: Blood-brain barrier; LGG: Low-grade gliomas.}

\section{Acknowledgements}

Not applicable.

\section{Authors' contributions}

Conception and design: CL, CY, CK, XSZ, ZPC. Acquisition of data: CL, CY, YSC, SYX, JZ, FFC, YCL. Analysis and interpretation of data: CL, QYY, CCG, KS, JW. Drafting the article or revising it critically for important intellectual content: All authors. All authors read and approved the final manuscript.

\section{Funding}

National Natural Science Funds of China (NO. 81372685), National Basic Research Program of China (No. 2015CB755505), Guangzhou Science Technology Project (Nos. 201508020125 and 201803010056), and the Science and Technology Planning Project of Guangdong Province (No. 2016A020213004)

\section{Availability of data and materials}

The authenticity of this article has been validated by uploading the key raw data onto the Research Data Deposit public platform (www.researchdata.org. cn) with the approval RDD number RDDA2020001608. 


\section{Declarations}

\section{Ethics approval and consent to participate}

This study was approved by the Ethics Committee of the Sun Yatsen University Cancer Center (approval No. B2020-314-01), and written consents were obtained from the patients or the relatives of patients included in the study.

\section{Consent for publication}

Not applicable.

\section{Competing interests}

The authors declare that they have no competing interests.

\section{Author details}

'Sun Yat-Sen University Cancer Center, State Key Laboratory of Oncology in South China, Collaborative Innovation Center for Cancer Medicine, Guangzhou 510060, China. ${ }^{2}$ Department of Nuclear Medicine, The First Affiliated Hospital of Sun Yat-Sen University, Guangzhou 510080, China. ${ }^{3}$ Department of Neurosurgery, The First Affiliated Hospital of Shenzhen University/Shenzhen Second People's Hospital, Shenzhen 518035, China.

Received: 14 March 2021 Accepted: 24 May 2021 Published online: 31 May 2021

\section{References}

1. Ostrom QT, Cioffi G, Gittleman H, Patil N, Waite K, Kruchko C, et al. CBTRUS statistical report: primary brain and other central nervous system tumors diagnosed in the United States in 2012-2016. Neuro Oncol. 2019;21(Suppl 5):v1-100. https://doi.org/10.1093/neuonc/noz150.

2. Wen PY, Kesari S. Malignant gliomas in adults. N Engl J Med. 2008;359(5):492-507. https://doi.org/10.1056/NEJMra0708126.

3. Hygino da Cruz LC Jr, Rodriguez I, Domingues RC, Gasparetto EL, Sorensen AG. Pseudoprogression and pseudoresponse: imaging challenges in the assessment of posttreatment glioma. AJNR Am J Neuroradiol. 2011;32(11):1978-85. https://doi.org/10.3174/ajnr.A2397.

4. Liu J, Li C, Chen Y, Lv X, Lv Y, Zhou J, et al. Diagnostic performance of multiparametric MRI in the evaluation of treatment response in glioma patients at 3T. J Magn Reson Imaging. 2020;51(4):1154-61. https://doi. org/10.1002/jmri.26900.

5. Prager AJ, Martinez N, Beal K, Omuro A, Zhang Z, Young RJ. Diffusion and perfusion MRI to differentiate treatment-related changes including pseudoprogression from recurrent tumors in high-grade gliomas with histopathologic evidence. AJNR Am J Neuroradiol. 2015;36(5):877-85. https://doi.org/10.3174/ajnr.A4218.

6. Zhang L. Glioma characterization based on magnetic resonance imaging: challenge overview and future perspective. Glioma. 2020;3(2):61-6. https://doi.org/10.4103/glioma.glioma_9_20.

7. He Q, Zhang L, Zhang B, Shi X, Yi C, Zhang X. Diagnostic accuracy of (13) $\mathrm{N}$-ammonia PET, (11)C-methionine PET and (18)F-fluorodeoxyglucose PET: a comparative study in patients with suspected cerebral glioma. BMC Cancer. 2019;19(1):332. https://doi.org/10.1186/s12885-019-5560-1.

8. Humbert O, Bourg V, Mondot L, Gal J, Bondiau PY, Fontaine D, et al. (18) F-DOPA PET/CT in brain tumors: impact on multidisciplinary brain tumor board decisions. Eur J Nucl Med Mol Imaging. 2019;46(3):558-68. https:// doi.org/10.1007/s00259-018-4240-8

9. Xiangsong Z, Weian C. Differentiation of recurrent astrocytoma from radiation necrosis: a pilot study with $13 \mathrm{~N}-\mathrm{NH} 3 \mathrm{PET}$. J Neurooncol. 2007:82(3):305-11. https://doi.org/10.1007/s11060-006-9286-y.

10. Pauleit D, Stoffels G, Bachofner A, Floeth FW, Sabel M, Herzog H, et al. Comparison of (18)F-FET and (18)F-FDG PET in brain tumors. Nucl Med Biol. 2009;36(7):779-87. https://doi.org/10.1016/j.nucmedbio.2009.05.005.

11. Albert NL, Weller M, Suchorska B, Galldiks N, Soffietti R, Kim MM, et al. Response assessment in neuro-oncology working group and European Association for neuro-oncology recommendations for the clinical use of PET imaging in gliomas. Neurol Oncol. 2016;18(9):1199-208. https://doi. org/10.1093/neuonc/now058.
12. Libert LC, Franci X, Plenevaux AR, Ooi T, Maruoka K, Luxen AJ, et al. Production at the curie level of no-carrier-added 6-18F-fluoro-L-dopa. J Nucl Med. 2013;54(7):1154-61. https://doi.org/10.2967/jnumed.112.112284.

13. Shi X, Yi C, Wang X, Zhang B, Chen Z, Tang G, et al. 13N-ammonia combined with $18 \mathrm{~F}-\mathrm{FDG}$ could discriminate between necrotic high-grade gliomas and brain abscess. Clin Nucl Med. 2015;40(3):195-9. https://doi. org/10.1097/RLU.0000000000000649.

14. Shi X, Liu Y, Zhang X, Yi C, Wang X, Chen Z, et al. The comparison of $13 \mathrm{~N}$-ammonia and 18F-FDG in the evaluation of untreated gliomas. Clin Nucl Med. 2013;38(7):522-6. https://doi.org/10.1097/RLU.0b013e3182 95298d.

15. Wen PY, Macdonald DR, Reardon DA, Cloughesy TF, Sorensen AG, Galanis E, et al. Updated response assessment criteria for high-grade gliomas: response assessment in neuro-oncology working group. J Clin Oncol. 2010;28(11):1963-72. https://doi.org/10.1200/JCO.2009.26.3541.

16. Lv Y, Zhou J, Lv X, Tian L, He H, Liu Z, et al. Dual-energy spectral CT quantitative parameters for the differentiation of Glioma recurrence from treatment-related changes: a preliminary study. BMC Med Imaging. 2020;20(1):5. https://doi.org/10.1186/s12880-019-0406-5.

17. Jakobsen JN, Urup T, Grunnet K, Toft A, Johansen MD, Poulsen SH, et al. Toxicity and efficacy of lomustine and bevacizumab in recurrent glioblastoma patients. J Neurooncol. 2018;137(2):439-46. https://doi.org/10. 1007/s11060-017-2736-X.

18. Xu T, Chen J, Lu Y, Wolff JE. Effects of bevacizumab plus irinotecan on response and survival in patients with recurrent malignant glioma: a systematic review and survival-gain analysis. BMC Cancer. 2010;10:252. https://doi.org/10.1186/1471-2407-10-252.

19. Young RJ, Gupta A, Shah AD, Graber JJ, Chan TA, Zhang Z, et al. MRI perfusion in determining pseudoprogression in patients with glioblastoma. Clin Imaging. 2013;37(1):41-9. https://doi.org/10.1016/j.clinimag.2012.02. 016.

20. Li C, Gan Y, Chen H, Chen Y, Deng Y, Zhan W, et al. Advanced multimodal imaging in differentiating glioma recurrence from post-radiotherapy changes. Int Rev Neurobiol. 2020;151:281-97. https://doi.org/10.1016/bs. irn.2020.03.009.

21. Galldiks N, Langen KJ, Pope WB. From the clinician's point of view-what is the status quo of positron emission tomography in patients with brain tumors? Neuro Oncol. 2015;17(11):1434-44. https://doi.org/10.1093/ neuonc/nov118.

22. Galldiks N, Law I, Pope WB, Arbizu J, Langen KJ. The use of amino acid PET and conventional MRI for monitoring of brain tumor therapy. Neuroimage Clin. 2017;13:386-94. https://doi.org/10.1016/j.nicl.2016.12.020.

23. Jager PL, Vaalburg W, Pruim J, de Vries EG, Langen KJ, Piers DA. Radiolabeled amino acids: basic aspects and clinical applications in oncology. J Nucl Med. 2001;42(3):432-45.

24. Martinez-Amador N, Jimenez-Bonilla J, Martinez-Rodriguez I, De ArcochaTorres M, Quirce R, Gomez-de la Fuente FJ, et al. Value of the visual and semiquantitative analysis of carbon-11-methionine PET/CT in brain tumors' recurrence versus post-therapeutic changes. Nucl Med Commun. 2017;38(12):1125-32. https://doi.org/10.1097/MNM.0000000000000754.

25. Hotta M, Minamimoto R, Miwa K. 11C-methionine-PET for differentiating recurrent brain tumor from radiation necrosis: radiomics approach with random forest classifier. Sci Rep. 2019;9(1):15666. https://doi.org/10.1038/ s41598-019-52279-2.

26. D'Souza MM, Sharma R, Jaimini A, Panwar P, Bansal A, Tripathi M, et al. Metabolic assessment of intracranial tuberculomas using 11C-methionine and 18F-FDG PET/CT. Nucl Med Commun. 2012;33(4):408-14. https://doi.org/10.1097/MNM.0b013e32834f9b14.

27. Bashir A, Mathilde Jacobsen S, Molby Henriksen O, Broholm H, Urup T, Grunnet K, et al. Recurrent glioblastoma versus late posttreatment changes: diagnostic accuracy of O-(2- [18F]fluoroethyl)-Ltyrosine positron emission tomography (18F-FET PET). Neuro Oncol. 2019;21(12):1595-606. https://doi.org/10.1093/neuonc/noz166.

28. Bogsrud TV, Londalen A, Brandal P, Leske H, Panagopoulos I, Borghammer $\mathrm{P}$, et al. 18F-fluciclovine PET/CT in suspected residual or recurrent highgrade glioma. Clin Nucl Med. 2019;44(8):605-11. https://doi.org/10.1097/ RLU.0000000000002641.

29. Nikaki A, Angelidis G, Efthimiadou R, Tsougos I, Valotassiou V, Fountas K, et al. (18)F-fluorothymidine PET imaging in gliomas: an update. Ann Nucl Med. 2017;31(7):495-505. https://doi.org/10.1007/s12149-017-1183-2. 
30. Schelhaas S, Heinzmann K, Bollineni VR, Kramer GM, Liu Y, Waterton JC, et al. Preclinical applications of 3'-deoxy-3'- [(18)F]fluorothymidine in oncology-a systematic review. Theranostics. 2017;7(1):40-50. https:// doi.org/10.7150/thno.16676.

31. McKinley ET, Ayers GD, Smith RA, Saleh SA, Zhao P, Washington MK, et al. Limits of [18F]-FLT PET as a biomarker of proliferation in oncology. PLOS ONE. 2013:8(3):e58938. https://doi.org/10.1371/journal.pone.0058938.

32. Tripathi M, Sharma R, D'Souza M, Jaimini A, Panwar P, Varshney R, et al. Comparative evaluation of F-18 FDOPA, F-18 FDG, and F-18 FLT-PET/ CT for metabolic imaging of low grade gliomas. Clin Nucl Med. 2009;34(12):878-83. https://doi.org/10.1097/RLU.0b013e3181becfe0.

33. Enslow MS, Zollinger LV, Morton KA, Butterfield RI, Kadrmas DJ, Christian $\mathrm{PE}$, et al. Comparison of 18F-fluorodeoxyglucose and 18F-fluorothymidine PET in differentiating radiation necrosis from recurrent glioma. Clin Nucl Med. 2012;37(9):854-61. https://doi.org/10.1097/RLU.0b013e3182 62c76a.

34. Hirata K, Yamaguchi S, Shiga T, Kuge Y, Tamaki N. The roles of hypoxia imaging using (18)F-fluoromisonidazole positron emission tomography in glioma treatment. J Clin Med. 2019;8(8):1088. https://doi.org/10.3390/ jcm8081088.

35. Zhuang H, Shi S, Yuan Z, Chang JY. Bevacizumab treatment for radiation brain necrosis: mechanism, efficacy and issues. Mol Cancer. 2019;18(1):21 https://doi.org/10.1186/s12943-019-0950-1.

36. Yamaguchi S, Hirata K, Toyonaga T, Kobayashi K, Ishi Y, Motegi H, et al. Change in 18F-fluoromisonidazole PET is an early predictor of the prognosis in the patients with recurrent high-grade glioma receiving bevacizumab treatment. PLoS ONE. 2016;11(12):e167917. https://doi.org/ 10.1371/journal.pone.0167917.

37. Kessler J, Hohmann T, Guttler A, Petrenko M, Ostheimer C, Hohmann $U$, et al. Radiosensitization and a less aggressive phenotype of human malignant glioma cells expressing isocitrate dehydrogenase 1 (IDH1) mutant protein: dissecting the mechanisms. Cancers (Basel). 2019;11(6):889. https://doi.org/10.3390/cancers11060889.

38. Nael K, Bauer AH, Hormigo A, Lemole M, Germano IM, Puig J, et al. Multiparametric MRI for differentiation of radiation necrosis from recurrent tumor in patients with treated glioblastoma. AJR Am J Roentgenol. 2018;210(1):18-23. https://doi.org/10.2214/AJR.17.18003.

39. Mihovilovic Ml, Kertels $\mathrm{O}$, Hanscheid H, Lohr M, Monoranu CM, Kleinlein I, et al. O-(2-((18)F)fluoroethyl)-L-tyrosine PET for the differentiation of tumour recurrence from late pseudoprogression in glioblastoma. J Neurol Neurosurg Psychiatry. 2019;90(2):238-9. https://doi.org/10.1136/ jnnp-2017-317155.

\section{Publisher's Note}

Springer Nature remains neutral with regard to jurisdictional claims in published maps and institutional affiliations.
Ready to submit your research? Choose BMC and benefit from:

- fast, convenient online submission

- thorough peer review by experienced researchers in your field

- rapid publication on acceptance

- support for research data, including large and complex data types

- gold Open Access which fosters wider collaboration and increased citations

- maximum visibility for your research: over $100 \mathrm{M}$ website views per year

At BMC, research is always in progress.

Learn more biomedcentral.com/submissions 